\title{
PENGARUH KEPUASAN KERJA, STRES KERJA, DAN LINGKUNGAN KERJA NON FISIK TERHADAP TURNOVER INTENTION
}

\author{
Desak Putu Rijasawitri ${ }^{1}$ \\ I Wayan Suana ${ }^{2}$ \\ ${ }^{1,2}$ Fakultas Ekonomi dan Bisnis Universitas Udayana (Unud), Bali, Indonesia \\ email: desakrijasawitri@yahoo.co.id
}

\begin{abstract}
ABSTRAK
Penelitian ini bertujuan untuk menguji pengaruh kepuasan kerja, stres kerja, lingkungan kerja terhadap turnover intention. Penelitian ini dilakukan di PT. Kwalita Bali Kabupaten Gianyar. Jumlah responden pada penelitaian ini adalah sebanyak 35 orang. Pengumpulan data dalam penelitian ini adalah dengan penyebaran kuesioner menggunakan Skala Likert 5 poin untuk mengukur 17 indikator dan empat variabel penelitian penelitian dan teknik analisis data yang digunakan pada penelitian ini adalah analisis regresi linier berganda. Hasil penelitian ini membuktikan bahwa kepuasan kerja berpengaruh negatif terhadap turnover intention artinya semakin tinggi tingkat kepuasan kerja karyawan maka tingkat turnover intention semakin rendah. Selanjutnya stres kerja berpengaruh positif terhadap turnover intention artinya semakin tinggi tingkat stres yang dialami karyawan maka turnover intention akan semakin meningkat. Terakhir lingkungan kerja non fisik berpengaruh negatif terhadap turnover intention dimana semakin baik dan nyaman lingkungan kerja maka tingkat turnover intention semakin rendah.
\end{abstract}

Kata kunci: kepuasan kerja, stre kerja, lingkungan kerja, turnover intention

\begin{abstract}
This study aims to examine the effect of job satisfaction, job stress, work environment on turnover intention. This research was conducted at PT. Kwalita Bali, Gianyar Regency. The number of respondents in this study were 35 people. Data collection in this study is by distributing questionnaires using a 5-point Likert Scale to measure 17 indicators and four research variables and the data analysis technique used in this study is multiple linear regression analysis. The results of this study prove that job satisfaction has a negative effect on turnover intention, meaning that the higher the level of employee job satisfaction, the lower the level of turnover intention. Furthermore, work stress has a positive effect on turnover intention, meaning that the higher the level of stress experienced by employees, the turnover intention will increase. Finally the non-physical work environment has a negative effect on turnover intention where the better and more comfortable the work environment, the lower the level of turnover intention.

Keywords: job satisfaction, work stress, work environment, turnover intention
\end{abstract}




\section{PENDAHULUAN}

Karyawan merupakan elemen penting dalam perusahaan karena kinerjanya akan berdampak pada kegiatan operasional perusahaan. Apabila kinerja karyawan rendah, maka akan menjadi hambatan perusahaan dalam mencapai tujuannya (Ariana \& Riana, 2013). Hal tersebut membuat perusahaan melakukan beberapa kegiatan seperti merekrut, menyeleksi, melatih, dan mempertahankan karyawan yang berkualitas dan memiliki kinerja yang optimal. Perusahaan perlu memperhatikan karyawan mereka agar dapat berkontribusi dengan baik terhadap perusahaan. Karyawan yang tidak mendapat perhatian dari perusahaan dan kebutuhannya tidak terpuaskan biasanya akan memilih untuk meninggalkan pekerjaan mereka (turnover).

Turnover adalah berhentinya atau penarikan diri seseorang karyawan dari tempat bekerja (Sari, 2014). Turnover dalam dunia bisnis merupakan hal yang wajar, tetapi hal tersebut bisa menjadi indikasi masalah bagi perusahaan jika terjadi turnover karyawan yang tinggi. Perusahaan yang memiliki turnover tinggi harus mengeluarkan biaya yang lebih besar dalam melakukan kegiatan rekrutmen, penyeleksian, dan pelatihan karyawan baru, tentu hal ini akan mempengaruhi kinerja keuangan perusahaan. Biaya yang timbul akibat turnover yang tinggi akan membebani perusahaan dan berdampak pada performa perusahaan baik secara keuangan maupun non keuangan.

Sutanto \& Gunawan (2013) banyak penyebab terjadinya turnover intention antara lain stres kerja, lingkungan kerja, kepuasan kerja, komitmen organisasional, dan lain sebagainya. Turnover Intention memiliki dampak negatif bagi organisasi karena menciptakan ketidakstabilan terhadap kondisi tenaga kerja, menurunnya produktivitas karyawan, suasana kerja yang tidak kondusif dan juga berdampak pada meningkatnya biaya sumber daya manusia (Dharma, 2013).

Turnover merupakan masalah klasik yang selalu dihadapi para pengusaha. Seperti halnya replacement yang terus berjalan, baik replacement (pergantian) karena faktor umur maupun pengunduran diri. Jika pergantian disebabkan oleh faktor umur, maka perusahaan dapat mengantisipasi dengan mempersiapkan kader-kader untuk menggantikan posisi karyawan tersebut.

Tingginya tingkat turnover karyawan pada perusahaan dapat dilihat dari seberapa besar keinginan berpindah yang dimiliki karyawan suatu organisasi atau perusahaan (Putra, 2012). Turnover intention pada karyawan dapat berdampak buruk pada organisasi apalagi jika berujung pada keputusan karyawan meninggalkan organisasi (turnover) Manurung \& Ratnawati (2012) oleh karena itu perlu diketahui faktor-faktor yang dapat berpengaruh pada turnover intention sehingga kecenderungan terjadinya turnover dapat ditekankan. Beberapa penelitian dan literatur yang ada menunjukan bahwa turnover intention terkait dengan kepuasan kerja, stres kerja, dan lingkungan kerja.

Sejalan dengan kondisi tersebut, maka PT. Kwalita Bali yang merupakan salah satu perusahaan export handicraft di Bali yang beralamatkan di Jl. By Pass Ida Bagus Mantra No. 468, Ketewel Kabupaten Gianyar ini menawarkan berbagai produk kerajinan lokal untuk di jual di pasar dunia. Kwalita Bali memiliki pembeli dari berbagai negara di dunia seperti Asia, Amerika, Australia dan Eropa. Kwalita Bali selalu menawarkan produk baru yang selalu disesuaikan dengan 
permintaan pasar dan trend saat ini. Selain itu karyawan pada PT. Kwalita Bali selalu dituntut untuk meningkatkan kemampuan dalam menghadapi persaingan, salah satunya adalah dengan memperhatikan faktor tenaga kerja.

Harnoto (2002) (dalam Sianipar \& Haryanti, 2014) menjelaskan tanda-tanda karyawan melakukan turnover adalah absensi yang meningkat, mulai malas bekerja, peningkatan pelanggaran terhadap tata tertib kerja, meningkatnya protes terhadap atasan, dan prilaku positif yang sangat berbeda dari biasanya. Berdasarkan observasi yang dilakukan, PT. Kwalita Bali menghadapi masalah dalam bidang turnover intention. Hal ini dapat dilihat dari banyaknya karyawan yang sering melanggar tata tertib perusahaan, seperti seringnya karyawan yang datang terlambat untuk bekerja. Selain itu penurunan kinerja juga dialami oleh karyawan, menurut direktur perusahaan dalam proses penentuan harga ke buyer sering kali para merchandiser salah menentukan harga jual dan mengakibatkan penurunan margin bagi perusahaan. Faktor lain yang menyebabkan tingginya tingkat turnover intention adalah banyaknya karyawan yang merasa bahwa gaji yang mereka terima tidak sesuai dengan pekerjaan yang mereka lakukan sehingga sering terjadi protes yang dilakukan karyawan terkait dengan hal tersebut.

PT. Kwalita Bali merupakan perusahaan yang bergerak di bidang export handicraft, dengan jumlah karyawan sebanyak 35 orang. Namun PT. Kwalita Bali menghadapi masalah mengenai adanya keinginan karyawan untuk keluar dari perusahaan (turnover intention). Hal tersebut dapat dilihat dari data absensi karyawan rata-rata mencapai 9,1 persen per bulan.

Ardana et al. (2012) bahwa rata-rata tingkat absensi 2 sampai 3 persen per bulan masih dianggap baik, sedangkan tingkat absensi yang mencapai 15 sampai 20 persen per bulan sudah menunjukkan gejala yang sangat buruk. Tingkat absensi karyawan sebesar 9,1 persen menunjukkan gejala sangat buruk, yang menjadi salah satu indikasi terjadinya turnover.

Tingginya turnover intention karyawan pada PT. Kwalita Bali disebabkan oleh berbagai faktor, salah satunya adalah kepuasan kerja. Berdasarkan observasi dan wawancara yang dilakukan peneliti, terlihat bahwa karyawan merasa pekerjaan yang mereka lakukan terasa berat dan hasil yang mereka peroleh tidak sesuai dengan pekerjaan yang mereka lakukan, sehingga mengakibatkan karyawan merasa malas untuk bekerja dan sering datang terlambat dalam bekerja. Menurut beberapa karywan, mereka yang ingin keluar mengharapkan gaji yang lebih tinggi, karena mereka merasa bahwa gaji yang diberikan perusahaan dirasa belum mencukupi untuk kebutuhan sehari-hari.

Kepuasan kerja merupakan perasaan positif tentang pekerjaan seseorang yang dihasilkan dari evaluasi karakteristik pekerjaan tersebut (Robbins et al. 2013). Kepuasan kerja merupakan perasaan emosional karyawan terhadap pekerjaannya (Kardam \& Rangnekar, 2012). Meningkatkan kepuasan karyawn adalah kunci suksesnya organisasi bisnis, hal tersebut merupakan dasar bagi perusahaan untuk melihat seperti apa keinginan karyawan, lingkungan kerja yang diinginkan dan dengan hal tersebut akan dapat meningkatkan pengabdian karyawan (Rizwan, 2014).

Penelitian Qureshi et al. (2013)menemukan adanya hubungan positif stres kerja terhadap turnover intention, dimana dengan meningkatnya stres kerja juga 
diikuti dengan meningkatnya turnover intention. Stres muncul saat karyawan tidak mampu memenuhi apa yang menjadi tuntutan-tuntutan pekerjaan, ketidakjelasan apa yang menjadi tanggung jawab pekerjaan, kekurangan waktu untuk menyelesaikan tugas, tidak ada dukungan fasilitas untuk menjalankan pekerjaan, tugas-tugas yang saling bertentangan, merupakan contoh pemicu stres. Dalam jangka panjang, karyawan yang tidak dapat menahan stres kerja maka karyawan tidak mampu lagi bekerja diperusahaan. Pada tahap yang semakin parah, stres bisa membuat karyawan menjadi sakit atau bahkan akan mengundurkan diri (turnover) (Manurung \& Ratnawati, 2012).

Stres kerja merupakan suatu gejala atau perasaan yang dapat timbul dalam diri seorang pekerja dan dapat memberikan dampak dalam suatu organisasi atau perusahaan, yang akan memberikan pengaruh terhadap kepuasan karyawan dan akan mempengaruhi kinerja karyawan (Chaudhry, 2012). Ketika stres kerja meningkat maka akan menyebabkan timbulnya keinginan keluar yang ada pada diri karyawan (Chandio et al. 2013). Stres merupakan isu utama yang menjadi perhatian karena telah menjadi bagian dari kehidupan karyawan dan sulit untuk menghindari stres dari pekerjaan (Parvaiz et al., 2015).

Selain kepuasan kerja dan stres kerja, lingkungan kerja merupakan salah satu faktor yang paling menentukan keberhasilan perusahaan. Selain beban kerja, terdapat faktor lain yang mempengaruhi turnover intention yaitu lingkungan kerja. (Widodo, 2014) menyebutkan bahwa lingkungan kerja merupakan sesuatu di luar organisasi yang berpotensi mempengaruhi karyawan dalam melakukan pekerjaan dan pada akhirnya mempengaruhi kinerja organisasi. Organisasi diminta harus bisa memberikan rasa nyaman dan aman bagi setiap karyawan di dalam melakukan pekerjaannya (Febriani \& Indrawati, 2013). Putra \& Rahyuda (2016) menyatakan bahwa lingkungan kerja adalah suatu tempat atau kondisi dimana karyawan melakukan aktivitas secara baik jika lingkungan tersebut terasa nyaman, aman dan bersih yang nantinya dapat menentukan keberhasilan suatu perusahaan.

Karyawan dapat melaksanakan tugas dan pekerjaannya dipengaruhi oleh banyak faktor, sehingga ada karyawan yang bersemangat dan kurang bersemangat dalam bekerja. Selain itu, hubungan antar karyawan dan hubungan dengan atasan merupakan faktor penting dalam kenyamanan karyawan dalam bekerja. Lingkungan kerja yang kondusif meningkatkan motivasi kerja dan pada akhirnya meningkatkan prestasi kerja (Sari, 2012). Dalam penelitian Qureshi et al. (2013) lingkungan kerja memiliki hubungan negatif dengan tunover intention, yang menunjukan kondisi kerja yang baik dapat mengurangi jumlah turnover intention.

Rahmawanti et al. (2014) menyatakan agar dapat mencapai tujuan, perusahaan harus menciptakan lingkungan kerja yang baik secara fisik dan non fisik. Keseluruhan dari faktor intern dan ekstern yang ada di sekitar tempat kerja setiap karyawan berupa tempat fisik seperti kursi, meja serta peralatan kerja lainnya yang dapat mempengaruhi karyawan di dalam melaksanakan tugas dan pekerjaannya sehari-hari disebut dengan lingkungan kerja fisik (Rumada \& Utama, 2013). Dalam penelitian ini lebih menekankan variabel lingkungan kerja non fisik, karena lingkungan kerja non fisik berkaitan erat dengan hubungan pekerja dengan manajemen atau rekan kerja, tingkat kesejahteraan terutama manfaat non tunai, serta faktor yang terkait dengan tempat pekerja (Taiwo, 2010). 
Menurut Wursanto (2009) lingkungan kerja non fisik dapat dirasakan oleh para pekerja melalui hubungan - hubungan sesama pekerja maupun dengan atasan.

Beberapa pendapat di atas menunjukan bahwa kepuasan kerja, stres kerja, dan lingkungan kerja mampu mempengaruhi turnover intention karyawan. Tujuan dari penelitian ini adalah untuk mengetahui faktor-faktor yang mempengaruhi turnover intention karyawan pada PT. Kwalita Bali, dimana penelitian ini akan menguji pengaruh kepuasan kerja, stres kerja dan lingkungan kerja terhadap turnover intention. Syahronica et al. (2015) bahwa kepuasan kerja memiliki hubungan yang negatif terhadap turnover intention. Hasil penelitian Indrayanti \& Riana (2016) didukung pula oleh penelitian Sari et al. (2015) yang menyatakan adanya pengaruh negatif antara kepuasan kerja dengan turnover intention, dimana karyawan yang mencapai kepuasan kerja akan berusaha untuk tetap berada di dalam perusahaan. Kepuasan kerja berpengaruh negatif terhadap keinginan berpindah kerja karyawan (turnover intention) yang mengindikasikan bahwa kepuasan kerja yang rendah mempengaruhi tingginya turnover intention karyawan (Yaqin, 2013). Kabungaidze et al. (2013) yang menyatakan, bahwa karyawan yang tidak puas dengan pekerjaan mereka, akan mengalami sikap negatif terhadap pekerjaan mereka dan sikap positif terhadap turnover intention, jadi semakin tinggi tingkat kepuasan kerja karyawan maka semakin rendah tingkat turnover intention karyawan.

$\mathrm{H}_{1}$ : Kepusan kerja berpengaruh negatif terhadap turnover intention

Penelitian Parvaiz et al. (2015) juga menunjukan stres kerja memiliki hubungan positif dan signifikan dengan turnover intention. Jika karyawan mengalami stres kerja dan tidak memiliki mekanisme yang cocok untuk mengatasi stres kerja tersebut, maka akan menimbulkan keinginan karyawan untuk keluar. Jadi, dapat disimpulkan bahwa stres kerja merupakan salah satu variabel yang berpengaruh positif dan signifikan terhadap turnover intention, dimana semakin tinggi tekanan dalam pekerjaan, maka tingkat stres pada karyawan akan meningkat, sehingga terdapat kecenderungan karyawan berfikir untuk meninggalkan perusahaan.

Hasil penelitian Saeka (2016), didukung pula oleh penelitian Alamsyah \& Kusumadewi (2016), serta Sari et al. (2016) yang mengemukakan bahwa stres kerja memiliki pengaruh positif terhadap turnover intention. Didalam penelitian Mamewe (2015) mendapatkan hasil stres kerja berpengaruh terhadap niat keluar karyawan, semakin tinggi tingkat stres kerja yang dirasakan karyawan semakin besar niat karyawan untuk meninggalkan organisasi. Siddiqui \& Raja (2015) dalam penelitiannya menunjukan bahwa stres kerja berpengaruh positif dan signifikan terhadap turnover intention karena tekanan yang berlebihan dan saraf ketegangan membuat karyawan berfikir untuk meninggalkan organisasi.

$\mathrm{H}_{2}$ : Stres kerja berpengaruh positif terhadap turnover intention.

Penelitian Qureshi et al. (2013) lingkungan kerja memiliki pengaruh negatif terhadap turnover intention, yang menunjukkan kondisi kerja yang baik dapat mengurangi turnover intention. Verina (2014) menemukan bahwa lingkungan kerja secara parsial berpengaruh negatif terhadap turnover intention karyawan. Semakin tinggi kenyamanan lingkungan kerja yang dirasakan oleh 
karyawan, maka turnover intention karyawan akan menurun. Perpindahan karyawan dapat dikaitkan salah satunyadengan kehidupan kerja yang ada di dalam perusahaan. Lingkungan kerja yang memiliki hubungan antar karyawan dan atasan yang harmonis, serta didukung sarana dan prasarana memadai memberikan dampak positif bagi karyawan untuk tetap tinggal di perusahaan. Hal ini didukung oleh hasil penelitian yang dilakukan oleh Verina (2014) bahwa lingkungan kerja berpengaruh negatif signifikan terhadap turnover intention karyawan.

$\mathrm{H}_{3}$ : Lingkungan kerja non fisik berpengaruh negatif dan signifikan terhadap turnover intention.

Turnover intention merupakan masalah yang sering timbul pada sebuah organisasi yang menyangkut keinginan keluarnya karyawan dalam sebuah organisasi (Ksama, 2016). Mobley (1986), turnover intention diartikan sebagai kecendrungan atau niat kariawan untuk berhenti bekerja dari pekerjaanya secara sukarela atau pindah kerja dari satu tempat kerja ke tempat keja yang lain sesuai pilihannya sendiri. Sianipar \& Haryanti (2014) turnover intention adalah niat seseorang berhenti dari suatu perusahaan karena suatu alasan baik secara sukarela (berasal dari diri sendiri) maupun secara tidak sukarela (pemutusan hubungan kerja dari perusahaan).

Terkadang di dalam perusahaan ada karyawan yang tidak mengerahkan seluruh kemampuan yang dimiliki untuk mencapai tujuan perusahaan karena adanya keinginan untuk keluar atau pindah ke perusahaan lain (turnover intention) untuk mendapatkan pekerjaan yang lebih baik. Turnover intention dapat diartikan sebagai niat karyawan untuk keluar dari organisasi, baik dalam bentuk pengunduran diri maupun pemberhentian. Turnover menjadi kendala yang harus diterima oleh semua organisasi, karena saat ini sulit mencari tenaga kerja yang memiliki keterampilan serta komitmen yang tinggi terhadap organisasi (Jehanzeb et al. 2013). Sutanto \& Gunawan (2013) banyak penyebab terjadinya turnover intention antara lain kepuasan kerja, stres kerja, lingkungan kerja dan lain sebagainya. Dalam penelitian Chen (2006) terungkap bahwa ada dua faktor yang berpengaruh pada turnover intention, yaitu kepuasan kerja dan komitmen organisasional.

Berdasarkan teori traditional turnover munculnya fenomena turnover disebabkan oleh faktor sikap yaitu kepuasan kerja dan komitmen organisasional (Zhao \& Liu, 2010). Salah satu teori yang digunakan dalam penelitian ini adalah traditional turnover theory. Zhao \& Liu (2010) menyatakan bahwa perilaku turnover pada karyawan dipengaruhi oleh kepuasan kerja dan komitmen organisasional sebagai variabel perantara. Menurut teori ini, karyawan dengan kepuasan kerja yang tinggi dan komitmen organisasional diyakini tidak mudah untuk meninggalkan pekerjaan mereka.

Harman et al. (2009) menyatakan bahwa traditional turnover theory mengindikasikan karyawan dapat meninggalkan pekerjaan karena perilaku kerja yang negatif, sementara Holtom \& O’Neill (2004) mengungkapkan bahwa traditional turnover theory berupaya menjelaskan tentang bagaimana seseorang 
merasakan ketidakpuasan dalam pekerjaannya. Ketidakpuasan kerja yang dirasakan oleh karyawan ini mengakibatkan karyawan tersebut akan mencari pekerjaan baru, membandingkan dengan pilihan mereka saat ini, dan kemudian pergi jika alternatif yang dirasa lebih baik dari situasi ini.

Turnover intention merupakan sikap atau tingkatan dimana individu karyawan memiliki sebuah pemikiran untuk meninggalkan atau mengundurkan diri dari organisasi secara sukarela dari pekerjaannya (Grant et al., 2001).

Kepuasan kerja merupakan tingkat kepuasan yang diraakan karyawan terkait dengan pekerjaan karyawan Puangyoykeaw \& Yuko (2015), Giauque (2014) kepuasan kerja merupakan respon individu terhadap pengalamnnya terhadap pengalamnnya dalam bekerja.

Penelitian yang luas terhadap kepuasan kerja menunjukan bahwa faktorfaktor pribadi seperti kebutuhan dan aspirasi individu menentukan kepuasan kerja ini, bersama dengan kelompok dan faktor organisasi seperti hubungan antara rekan kerja dan supervisor dan kondisi kerja, kebijakan kerja, dan kompensasi (Griffin \& Moorhead, 2014). Kepuasan atau ketidak puasan karyawan merupakan perbandingan antara apa yang diterima dalam bekerja.

Penelitian yang luas terhadap kepuasan kerja menunjukan bahwa faktorfaktor pribadi seperti kebutuhan dan aspirasi individu menentukan kepuasan kerja ini, bersama dengan kelompok dan faktor organisasi seperti hubungan antara rekan kerja dan supervisor dan kondisi kerja, kebijakan kerja, dan kompensasi (Griffin \& Moorhead, 2014). Karyawan dengan tingkat kepuasan rendah akan menunjukkan sikap negatif, baik terhadap pekerjaannya maupun terhadap lingkungan kerjanya, sehingga karyawan akan merasakan insecure dalam dirinya dan merasakan kegelisahan dalam pekerjaannya, hingga pada akhirnya karyawan akan memiliki niat untuk berpindah dan meninggalkan pekerjaannya (Hanafiah, 2014).

Menurut Bisen dan Priya terdapat tiga faktor utama yang mempengaruhi kepuasan kerja (Kaswan, 2015) yaitu: 1) Usia karyawan dalam kelompok usia yang lebih tinggi lebih puas daripada karyawan yang lebih muda. Karena pada saat ini mereka yang dalam usia lebih tua memiliki kehidupan yang stagnan, kehidupan mereka sudah mapan dan mereka telah memperoleh hampir semua yang mereka inginkan dibandingkan dengan karyawan yang lebih muda. 2) Jenis kelamin biasanya perempuan memiliki tingkat aspirasi dan ekspektasi yang lebih rendah daripada laki-laki. Oleh karena itu mereka lebih mudah puas dengan pekerjaanya. Salah satu alasan kepuasan itu adalah karena mereka tidak memiliki beban ekonomi seberat laki-laki. 3) Lamanya pengabdian karyawan pada tahap awal mengalami kepuasan kerja yang lebih besar, tetapi ketika mereka mencapai usia 45 tahun sampai 55 tahun, tingkat kepuasan kerja mereka menurun dan akan meningkat lagi setelah usia ini. 4) Kepribadian karyawan yang mampu berinteraksi dan berhubungan baik dengan atasannya, kolege, keluarga, dengan bos atau manajemen merasa lebih puas dibandingkan dengan mereka yang tidak seperti itu.5) Orang yang bergantung pencari nafkah dengan sedikit tanggungan 
(orang yang bergantung padanya) lebih puas terhadap pekerjaannya daripada mereka dengan tanggungan keluarga yang lebih besar. 6) Ambisius ketika kinerja dan ambisi karyawan tidak terpenuhi dari pekerjaan yang ada, maka hal itu akan menimbulkan ketidakpuasan. 7) Kemampuan mental jika karyawan memilki kemampuan mental yang tinggi dibandingkan persyaratan yang dituntut untuk pekerjaan tertentu, hal itu akan menimbulkan ketidakpuasan.

Stres merupakan isu utama yang menjadi perhatian karena telah menjadi bagian dari kehidupan karyawan dan sulit untuk menghindari stres dari pekerjaan (Parvaiz et al. 2015). Stres kerja yang terlalu tinggi dapat mengancam kemampuan seseorang untuk menghadapi kondisi lingkungan (Budiyono, 2016). Stres kerja perlu mendapatkan perhatian perusahaan karena tidak hanya berpengaruh pada individu, namun juga terhadap perusahaan secara keseluruhan (Waspodo et al., 2013). Stres terjadi ketika seseorang menerima sebuah kondis yang tidak diharapkan dari lingkungannya, sehingga menimbulkan reaksi-reaksi tertentu (Syahronica et al., 2015). Waspodo et al. (2013) stres kerja meruoakan suatu gejala yang dapat mempengaruhi seseorang dalam beraktivitas dalam bekerja. Mangkunegara (2000: dalam Sari, 2014) menyatakan bahwa stres kerja adalah perasaan yang menekan atau merasa tertekan yang dialami karyawan dalam menghadapi pekerjaan, stres kerja ini dapat menimbulkan emosi tidak stabil, perasaan tidak tenang, suka menyendiri, sulit tidur, merokok berlebihan, tidak bisa rileks, cemas, tegang, gugup, tekanan darah meningkat dan mengalami gangguan

Anatan \& Ellitan (2007) mengemukakan beberapa factor-faktor penyebab stres kerja diantaranya: 1) Extra Organizational stresor, yaitu penyebab stres dari luar organisasi meliputi perubahan sosial dan teknologi yang berakibatkan adanya perubahan gaya hidup masyarakat, perubahan ekonomi dan financial juga mempengaruhi pola kerja seseorang. 2) Organizational stresor, penyebab stres dari dalam organisasi yang meliputi kondisi kebijakan dan strategi administrasi, struktur dan design organisasi, proses organisasi dan kondisi lingkungan kerja. 3) Group stresor, penyebab stres dalam organisasi yang timbul akibat kurangnya kesatauan dalam melaksanakan tugas dan kerja terutama pada level bawah, kuranhnya dukungan dari atasan, munculnya konflik antar personal, interpersonal, dan antar kelompok. 4) Individual stresor, stres yang berakibat dari dalam diri individu yang muncul akibat konflik dan ambiguitas peran, beban kerja yang terlalu berat, dan kurangnya pengawasan dari pihak perusahaan.

Sari (2014) mengemukakan bahwa stres kerja diukur oleh beberapa hal, antara lain beban kerja terlalu berat, waktu kerja yang mendesak, kualitas pengawasan kerja yang rendah, iklim kerja yang tidak sehat, otoritas kerja yang tidak memadai yang berhubungan dengan tanggung jawab, konflik kerja, serta perbedaan nilai antara karyawan dengan pimpinan.

Widodo (2014) lingkungan kerja merupakan sesuatu di luar organisasi yang berpotensi mempengaruhi karyawan dalam melakukan pekerjaan dan pada akhirnya mempengaruhi kinerja organisasi. Organisasi diminta harus bisa 
memberikan rasa nyaman dan aman bagi setiap karyawan di dalam melakukan pekerjaannya (Febriani \& Indrawati, 2013). Putra \& Rahyuda (2016) menyatakan bahwa lingkungan kerja adalah suatu tempat atau kondisi dimana karyawan melakukan aktivitas secara baik jika lingkungan tersebut terasa nyaman, aman dan bersih yang nantinya dapat menentukan keberhasilan suatu perusahaan. (Anggun, 2013) mengungkapkan sikap kepemimpinan dan hubungan kerja karyawan yang merupakan bagian dari lingkungan kerja non fisik karyawan dapat membentuk motivasi intrinsik yang ada dalam diri karyawan saat melaksanakan pekerjaannya.

Dari beberapa pendapat diatas maka dapat disimpulkan bahwa lingkungan kerja merupakan segala sesuatu yang ada di sekitar karyawan pada saat bekerja, yang dapat mempengaruhi dirinya dan pekerjaanya masih dianggap baik, sedangkan tingkat absensi yang mencapai 15 sampai 20 persen per bulan sudah menunjukkan gejala yang sangat buruk. Tingkat absensi karyawan sebesar 9,1 persen menunjukkan gejala sangat buruk, yang menjadi salah satu indikasi terjadinya turnover.

Tingginya turnover intention karyawan pada PT. Kwalita Bali disebabkan oleh berbagai faktor, salah satunya adalah kepuasan kerja. Berdasarkan observasi dan wawancara yang dilakukan peneliti, terlihat bahwa karyawan merasa pekerjaan yang mereka lakukan terasa berat dan hasil yang mereka peroleh tidak sesuai dengan pekerjaan yang mereka lakukan, sehingga mengakibatkan karyawan merasa malas untuk bekerja dan sering datang terlambat dalam bekerja. Menurut beberapa karywan, mereka yang ingin keluar mengharapkan gaji yang lebih tinggi, karena mereka merasa bahwa gaji yang diberikan perusahaan dirasa belum mencukupi untuk kebutuhan sehari-hari.

Kepuasan kerja merupakan perasaan positif tentang pekerjaan seseorang yang dihasilkan dari evaluasi karakteristik pekerjaan tersebut (Robbins et al. 2013). Kepuasan kerja merupakan perasaan emosional karyawan terhadap pekerjaannya (Kardam \& Rangnekar, 2012). Meningkatkan kepuasan karyawn adalah kunci suksesnya organisasi bisnis, hal tersebut merupakan dasar bagi perusahaan untuk melihat seperti apa keinginan karyawan, lingkungan kerja yang diinginkan dan dengan hal tersebut akan dapat meningkatkan pengabdian karyawan (Rizwan, 2014).

Penelitian Qureshi et al. (2013)menemukan adanya hubungan positif stres kerja terhadap turnover intention, dimana dengan meningkatnya stres kerja juga diikuti dengan meningkatnya turnover intention. Stres muncul saat karyawan tidak mampu memenuhi apa yang menjadi tuntutan-tuntutan pekerjaan, ketidakjelasan apa yang menjadi tanggung jawab pekerjaan, kekurangan waktu untuk menyelesaikan tugas, tidak ada dukungan fasilitas untuk menjalankan pekerjaan, tugas-tugas yang saling bertentangan, merupakan contoh pemicu stres. Dalam jangka panjang, karyawan yang tidak dapat menahan stres kerja maka karyawan tidak mampu lagi bekerja diperusahaan. Pada tahap yang semakin parah, stres bisa membuat karyawan menjadi sakit atau bahkan akan mengundurkan diri (turnover) (Manurung \& Ratnawati, 2012). 
Stres kerja merupakan suatu gejala atau perasaan yang dapat timbul dalam diri seorang pekerja dan dapat memberikan dampak dalam suatu organisasi atau perusahaan, yang akan memberikan pengaruh terhadap kepuasan karyawan dan akan mempengaruhi kinerja karyawan (Chaudhry, 2012). Ketika stres kerja meningkat maka akan menyebabkan timbulnya keinginan keluar yang ada pada diri karyawan (Chandio et al. 2013). Stres merupakan isu utama yang menjadi perhatian karena telah menjadi bagian dari kehidupan karyawan dan sulit untuk menghindari stres dari pekerjaan (Parvaiz et al., 2015).

Selain kepuasan kerja dan stres kerja, lingkungan kerja merupakan salah satu faktor yang paling menentukan keberhasilan perusahaan. Selain beban kerja, terdapat faktor lain yang mempengaruhi turnover intention yaitu lingkungan kerja. (Widodo, 2014) menyebutkan bahwa lingkungan kerja merupakan sesuatu di luar organisasi yang berpotensi mempengaruhi karyawan dalam melakukan pekerjaan dan pada akhirnya mempengaruhi kinerja organisasi. Organisasi diminta harus bisa memberikan rasa nyaman dan aman bagi setiap karyawan di dalam melakukan pekerjaannya (Febriani \& Indrawati, 2013). Putra \& Rahyuda (2016) menyatakan bahwa lingkungan kerja adalah suatu tempat atau kondisi dimana karyawan melakukan aktivitas secara baik jika lingkungan tersebut terasa nyaman, aman dan bersih yang nantinya dapat menentukan keberhasilan suatu perusahaan.

Karyawan dapat melaksanakan tugas dan pekerjaannya dipengaruhi oleh banyak faktor, sehingga ada karyawan yang bersemangat dan kurang bersemangat dalam bekerja. Selain itu, hubungan antar karyawan dan hubungan dengan atasan merupakan faktor penting dalam kenyamanan karyawan dalam bekerja. Lingkungan kerja yang kondusif meningkatkan motivasi kerja dan pada akhirnya meningkatkan prestasi kerja (Sari, 2012). Dalam penelitian Qureshi et al. (2013) lingkungan kerja memiliki hubungan negatif dengan tunover intention, yang menunjukan kondisi kerja yang baik dapat mengurangi jumlah turnover intention.

\section{METODE PENELITIAN}

Lokasi penelitian ini adalah PT. Kwalita Bali yang beralamat di Jl. By Pass Ida Bagus Mantra No.468, Br. Rangkan, Ketewel, Sukawati, Gianyar. Lokasi ini dipilih karena ditemukannya masalah-masalah terkait turnover intention karyawan dipengaruhi oleh kepuasan kerja, stres kerja dan lingkungan kerja. Selain itu pemilihan lokasi penelitian ini didasarkan atas tersedianya data yang menandai dan mampu untuk diolah peneliti.

Populasi dari penelitian ini adalah karyawan di PT. Kwalita Bali, yang terdiri dari 27 orang karyawan kantor dan 8 orang karyawan gudang. Jadi total populasi pada penelitian ini adalah 35 orang, sedangkan pemilik perusahaan PT. Kwalita Bali tidak termasuk dalam responden penelitian karena pimpinan organisasi sudah memiliki komitmen tinggi untuk menjalankan perusahaan demi tercapainya tujuan perusahaan (Humala, 2014). Teknik pengambilan sample dalam penelitian ini memakai metode sampling jenuh, dimana seluruh populasi digunakan menjadi sampel penelitian ini.

Regresi linier berganda memiliki beberapa variabel bebas yang mempengaruhi variabel terikat yang jumlahnya hanya satu. Variabel bebas dalam penelitian ini adalah kepuasan kerja $\left(X_{1}\right)$, stres kerja $\left(X_{2}\right)$, dan lingkungan kerja 
$\left(X_{3}\right)$ sedangkan variabel terikat dalam penelitian ini adalah turnover intention $(\mathrm{Y})$. Adapun model regresi linier berganda dengan menggunakan persamaan sebagai berikut:

Keterangan:

$$
\mathrm{Y}=\alpha+\beta 1 \mathrm{X}_{1}+\beta 2 \mathrm{X}_{2}+\beta 3 \mathrm{X}_{3}+\mathrm{e}
$$

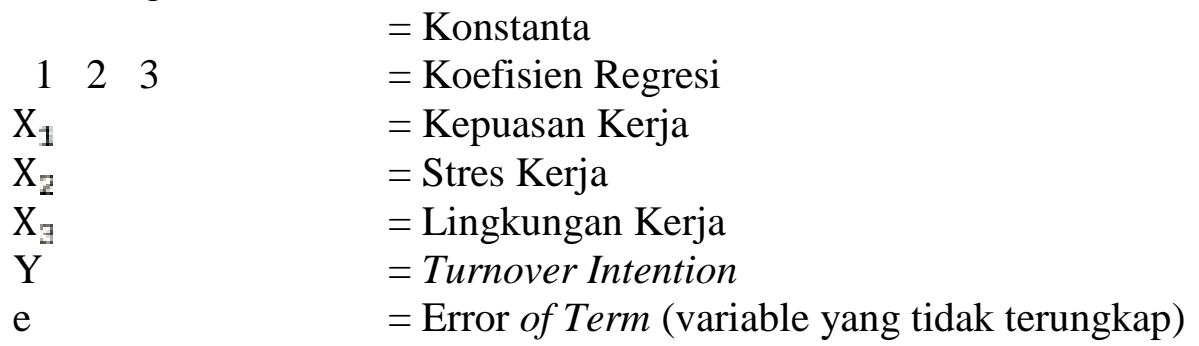

\section{HASIL DAN PEMBAHASAN}

Teknik analisis regresi berganda digunakan untuk menguji pengaruh dua atau lebih variabel independen terhadap satu variabel dependen. Hasil uji regresi linier berganda terhadap ketiga variabel independen yaitu kepuasan kerja, stres kerja dan lingkungan kerja dapat dilihat pada Tabel 1 berikut ini.

Tabel 1.

Hasil Analisis Regresi Linier Berganda

\begin{tabular}{|c|c|c|c|c|c|c|}
\hline \multirow{2}{*}{\multicolumn{2}{|c|}{ Model }} & \multicolumn{2}{|c|}{$\begin{array}{l}\text { Unstandardized } \\
\text { Coefficients }\end{array}$} & \multirow{2}{*}{$\begin{array}{l}\text { Standardized } \\
\text { Coefficients } \\
\text { Beta }\end{array}$} & \multirow[t]{2}{*}{$\mathbf{t}$} & \multirow[t]{2}{*}{ Sig. } \\
\hline & & B & Std. Error & & & \\
\hline \multirow{4}{*}{1} & $($ Constant $)$ & 5,536 & 0,853 & & 6,493 & 0,000 \\
\hline & Kepuasan Kerja & $-0,375$ & 0,121 & $-0,339$ & $-3,009$ & 0,004 \\
\hline & Stres Kerja & 0,290 & 0,138 & 0,230 & 2,108 & 0,043 \\
\hline & Lingkungan Kerja & $-0,496$ & 0,118 & $-0,450$ & $-4,192$ & 0,000 \\
\hline
\end{tabular}

Berdasarkan Tabel 1. model regresi yang digunakan adalah sebagai berikut:

$$
\mathrm{Y}=5,536-0,375 \mathrm{X}_{1}+0,290 \mathrm{X}_{2}-0,496 \mathrm{X}_{3}
$$

\begin{tabular}{|c|c|}
\hline$\alpha$ & $=$ Konstanta \\
\hline$\beta 1 \beta 2 \beta 3$ & $=$ Koefisien Regresi \\
\hline $\mathrm{X}_{1}$ & = Kepuasan Kerja \\
\hline$X_{2}$ & $=$ Stres Kerja \\
\hline$X_{3}$ & $=$ Lingkungan Kerja \\
\hline Y & $=$ Turnover Intention \\
\hline
\end{tabular}

Dimana:

Nilai koefisien regresi kepuasan kerja $\left(\mathrm{X}_{1}\right)$ sebesar $-0,375$ yang memiliki arti bahwa kepuasan kerja berpengaruh negatif terhadap turnover intention karyawan pada PT. Kwalita Bali, bila nilai kepuasan kerja $\mathrm{X}_{1}$ meningkat maka nilai dari turnover intention (Y) akan mengalami penurunan. 
Nilai koefisien regresi stres kerja $\left(\mathrm{X}_{2}\right)$ sebesar 0,290 yang memiliki arti bahwa stres kerja berpengaruh positif terhadap turnover intention karyawan pada PT. Kwalita Bali, bila nilai stres kerja $\mathrm{X}_{1}$ meningkat maka nilai dari turnover intention (Y) juga akan mengalami peningkatan.

Nilai koefisien regresi lingkungan kerja $\left(\mathrm{X}_{3}\right)$ sebesar -0,496 yang memiliki arti bahwa lingkungan kerja berpengaruh negatif terhadap turnover intention karyawan pada PT. Kwalita Bali, bila nilai lingkungan kerja $\mathrm{X}_{3}$ meningkat maka nilai dari turnover intention (Y) akan mengalami penurunan.

Uji Normalitas bertujuan untuk menguji apakah variabel-variabel yang digunakan dalam penelitian ini telah berdistribusi normal. Model regresi yang baik adalah model yang memiliki distribusi normal. Pengujian normalitas dapat dilakukan dengan menggunakan One Sample Kolmogorov-Smirnov Test, dengan taraf signifikan 0,05 atau 5 persen. Jika signifikan yang dihasilkan >0,005 maka distribusi datanya dikatakan normal. Sebaliknya jika signifikan yang dihasilkan $<0,05$ maka data tidak terdistribusi secara normal. Hasil perhitungan nilai Kolmogorov-Smirnov Test untuk model yang diperoleh dapat dilihat pada Tabel 2 berikut ini.

Tabel 2.

Hasil Uji Normalitas (Kolmogorov-Smirnov Test)

\begin{tabular}{llr}
\hline & \multicolumn{2}{c}{ Unstandardized Residual } \\
\hline $\mathrm{N}$ & & 35 \\
Normal Parameters ${ }^{a, b}$ & Mean & 0,0000000 \\
& Std. Deviation & 0,35711703 \\
& Absolute & 0,120 \\
Most Extreme Difference & Positive & 0,093 \\
& Negative & $-0,120$ \\
Kolmogorov-Smirnov $Z$ & & 0,713 \\
Asymp.Sig. (2-tailed) & & 0,690 \\
\hline Sumber: Data diolah, 2019 & &
\end{tabular}

Hasil uji normalitas Kolmogorov-Smirnov Test menunjukan bahwa berdasarkan nilai Sig (2-tailed), dapat dilihat bahwa besarnya Sig (2-tailed) $(0,690)>$ dari taraf signifikansi $(0,05)$, sehingga dapat disimpulkan bahwa variabel kepuasan kerja, stres kerja, dan lingkungan kerja terhadap turnover intention berdistribusi secara normal.

Uji multikolinearitas bertujuan untuk menguji apakah pada model regresi ditemukam adanya kolerasi antar variabel bebas atau independen. Untuk menguji adanya multikolinearitas dapat dilihat melalui nilai Variance Inflation Factor (VIF) dan Tolerance Value di atas 0,10 dan VIF kurang dari 10 maka dikatakan tidak terdapat gejala multikolinearitas. Hasil perhitungan nilai VIF untuk pengujian multikolinearitas antara sesama variabel bebas dapat dilihat pada Tabel 3.

Hasil uji Variance Inflation Factor (VIF) yang diperoleh dari Tabel 3 menunukan variabel bebas dalam model regresi tidak salaing berkorelasi. Diperoleh nilai VIF untuk masing-masing variabel bebas kurang dari 10 dan tolerance value berada di atas 0,10 . Hal ini menunjukan tidak adanya korelasi 
antara sesama variabel bebas dalam model regresi dan disimpulkan tidak terdapat masalah multikolinearitas diantara sesama variabel bebas dalam model regresi.

Tabel 3.

Hasil Uji Multikolinearitas

\begin{tabular}{|c|c|c|c|}
\hline \multirow{2}{*}{\multicolumn{2}{|c|}{ Model }} & \multicolumn{2}{|c|}{ Collinearity Statistic } \\
\hline & & Tollerance & $\begin{array}{c}\text { VIF } \\
\text { (Variance Inflation Factor Variance Inflation Factor) }\end{array}$ \\
\hline \multirow{4}{*}{1} & (Constant) & & \\
\hline & Kepuasan Kerja & 0,367 & 2,726 \\
\hline & Stres Kerja & 0,369 & 2,708 \\
\hline & Lingkugan Kerja & 0,383 & 2,612 \\
\hline
\end{tabular}

Uji heterokedastisitas bertujuan untuk menguji apakah dalam sebuah model regresi terjadi ketidaksamaan varian dari residual atau satu pengamatan ke pengamatan yang lain. Jika varian dari residual satu pengamatan ke pengamatan lain tetap, maka disebut homokedastisitas dan jika berbeda disebut heterokedastisitas. Untuk mendeteksi adanya heterokedastisitas pada penelitian ini menggunkan uji Glester. Pengujian ini membandingkan signifikasn dari uji ini apabila hasilnya Sig > 0,05 atau 5 persen. Jika signifikan diatas 5 persen maka disimpulkan model regresi tidak mengandung adanya heteroskedastisitas. Adapun hasil pengujian dapat dilihat pada Tabel 4 berikut ini.

Tabel 4.

Hasil Uji Heterokedastiditas

\begin{tabular}{|c|c|c|c|c|c|c|}
\hline \multirow{2}{*}{\multicolumn{2}{|c|}{ Model }} & \multicolumn{2}{|c|}{$\begin{array}{l}\text { Unstandardized } \\
\text { Coefficients }\end{array}$} & \multirow{2}{*}{$\begin{array}{l}\text { Standardized } \\
\text { Coefficients } \\
\text { Beta }\end{array}$} & \multirow[t]{2}{*}{$t$} & \multirow[t]{2}{*}{ Sig. } \\
\hline & & $B$ & Std. Error & & & \\
\hline \multirow[t]{4}{*}{1} & (Constant) & $-0,030$ & 0,565 & & $-0,054$ & 0,957 \\
\hline & Kepuasan Kerja & 0,066 & 0,080 & 0,242 & 0,825 & 0,416 \\
\hline & Stres Kerja & 0,043 & 0,091 & 0,139 & 0,474 & 0,639 \\
\hline & Lingkungan Kerja & $-0,018$ & 0,078 & $-0,067$ & $-0,234$ & 0,816 \\
\hline
\end{tabular}

Berdasarkan Tabel 4. didapatkan hasil perhitungan nilai signifikansi masing-masing variabel yang menunjukan level $\mathrm{Sig}>\alpha(0,05)$ yaitu 0,416 untuk kepuasan kerja, 0,639 untuk stres kerja dan 0,816 untuk lingkungan kerja. Hal ini berarti model regresi yang digunakan dalam penelitian ini terbebas dari heterokedastisitas.

Uji Koefisien Determinasi $\left(\mathrm{R}^{2)}\right.$ bertujuan untuk mengukur besarnya kontribusi variabel bebas kepuasan kerja, stres kerja, dan lingkungan kerja terhadap variabel terikat turnover intention. Besarnya nilai $\mathrm{R}$ square adalah sebesar 0,863 yang artinya sebesar 86,3 persen variasi turnover intention dipengaruhi oleh kepuasan kerja, stres kerja, dan lingkungan kerja. Sedangkan sisanya sebesar 14,7 persen dipngaruhi oleh faktor lain diluar model penelitian ini.

Uji kelayakan model (uji F) digunakan untuk mengetahui adanya pengaruh antara variabel bebas secara bersama-sama terhadap variabel terikat. Besarnya 
niali F statistik sebesar 65,264 dan nilai signifikannya sebesar 0,000 $\leq 0,05$ maka dapat disimpulkan adanya pengaruh yang signifikan antara kepuasan kerja, stres kerja, dan lingkungan kerja terhadap turnover intention. Dapat dilihat pada lampiran 7.

Kepuasan kerja memiliki nilai koefisien beta negatif sebesar -0,375, dengan signifikansi uji t sebesar 0,000 lebih kecil daripada $\alpha=0,05$, maka $\mathrm{H}_{0}$ ditolak. Hasil ini mendukung hipotesis $\mathrm{H}_{1}$ yang menyatakan bahwa kepuasan kerja berpengaruh negatif terhadap turnover intention pada karyawan PT. Kwalita Bali, dimana semakin tinggi kepuasan kerja pada karyawan maka semakin rendah terjadinya turnover intention.

Stres kerja memiliki nilai koefisien beta positif sebesar 0,290, dengan signifikansi uji t sebesar 0,000 lebih kecil dari $\alpha=0,05$ maka $\mathrm{H}_{0}$ ditolak. Hasil ini mendukung hipotesis $\mathrm{H}_{2}$ yang menyatakan stres kerja berpengaruh positif terhadap turnover intention pada karyawan PT. Kwalita Bali, dimana semakin tinggi tingkat stres kerja maka semakin tinggi juga tingkat tuenover intention yang terjadi.

Lingkungan kerja memiliki nilai koefisien beta positif sebesar -0,496, dengan signifikansi uji t sebesar 0,000 lebih kecil daripada $\alpha=0,05$, maka $\mathrm{H}_{0}$ ditolak. Hasil ini mendukung hipotesis $\mathrm{H}_{3}$ yang menyatakan bahwa lingkungan kerja berpengaruh negatif terhadap turnover intention pada karyawan PT. Kwalita Bali, dimana semakin nyaman lingkungan kerja maka semakin rendah tingkat terjadinya turnover intention.

Penelitian ini mendapatkan hasil yang sesuai dengan hipotesis satu $\left(\mathrm{H}_{1}\right)$ yang menyatakan bahwa kepuasan kerja berpengaruh negatif terhadap turnover intention. Hasil analisis uji hipotesis menunjukan bahwa kepuasan kerja memiliki pengaruh negatif dan signifikan terhadap turnover intention, dengan nilai koefisien regresi sebesar -0,375. Nilai negatif dari koefisien regresi variabel kepuasan kerja memiliki arti bahwa kepuasan kerja yang tinggi akan menurunkan tingkat turnover intention karyawan. Temuan ini didukung oleh hasil penelitian Chen (2006) menyatakan kepuasan kerja berpengaruh negatif terhadap turnover intentio dimana semakin puas karyawan dalam bekerja maka keinginan untuk meninggalkan organisasi semakin rendah. Irbayuni (2012) menyatakan bahwa kepuasan kerja mempunyai hubungan yang negatif dengan turnover intention.

Penelitian ini mendapatkan hasil yang sama dengan hipotesis dua $\left(\mathrm{H}_{2}\right)$ yang menyatakan bahwa stres kerja berpengaruh positif terhadap turnover intention. Hasil analisis uji hipotesis menunjukan bahwa stres kerja memiliki pengaruh positif dan signifikan terhadap turnover intention, dengan nilai koefisien regresi sebesar 0,290. Nilai positif dari koefisien regresi variabel stres kerja memiliki arti bahwa stres kerja yang tinggi akan meningkatkan turnover intention karyawan. Temuan ini didukung oleh hasil penelitian Iqbal et al. (2014) yang menyatakan bahwa stres kerja berpengaruh positif terhadap turnover intention. Waspodo et al. (2013) menemukan bahwa stres kerja memiliki pengaruh yang positif terhadap turnover intention ini artinya jika tingkat stres kerja meningkat maka keinginan 
karyawan untuk keluar dari organisasi juga semkain meningkat. Hasil ini juga didukung oleh pendapat Suciati et al. (2015) yang menunjukan bahwa stres kerja berpengaruh positif terhadap turnover intaention, Sewwandi \& Perere (2016) menyatakan bahwa stres kerja berpengaruh positif terhadap turnover intention.

Penelitian ini mendapatkan hasil yang sama dengan hipotesis dua $\left(\mathrm{H}_{3}\right)$ yang menyatakan bahwa lingkungan kerja berpengaruh negatif terhadap turnover intention. Hasil analisis uji hipotesis menunjukan bahwa lingkungan kerja memiliki pengaruh negatif dan signifikan terhadap turnover intention, dengan nilai koefisien regresi sebesar -0,496. Nilai negatif dari koefisien regresi variabel lingkungan kerja memiliki arti bahwa lingkungan kerja yang nyaman akan menurunkan tingkat turnover intention karyawan. Temuan ini didukung hasil penelitian yang dilakukan Yunita \& Putra (2015) yang menyatakan bahwa lingkungan kerja berpengaruh negatif terhadap turnover intention dengan nilai rata-rata terendah variabel lingkungan kerja terdapat pada indikator hubungan kerja. Verina (2014) menemukan bahwa lingkungan kerja secara parsial berpengaruh negatif terhadap turnover intention karyawan. Semakin tinggi kenyamanan lingkungan kerja yang dirasakan oleh karyawan, maka turnover intention karyawan akan menurun. Verina (2014) bahwa lingkungan kerja berpengaruh negatif signifikan terhadap turnover intention karyawan. Chairani (2014) membuktikan bahwa lingkungan kerja memiliki pengaruh negatif terhadap turnover intention

Penelitian ini mengkonfirmasi model pengaruh dari kepuasan kerja, stres kerja, dan lingkungan kerja terhadap turnover intention. Hasil dari model teoritis tersebut menjelaskan bahwa kepuasan kerja, stres kerja, dan lingkungan kerja secara langsung berpengaruh terhadap turnover intention. Hasil penelitian ini menelaskan pentingnya memperhatikan peran kepuasan kerja, stres kerja, dan lingkungan kerja agar dapat menekan terjadinya turnover intention sehingga dapat membantu perusahaan menekan biaya dan waktu untuk perekrutan dan pelatihan karyawan baru.

Penelitian ini telah dilaksanakan sesuai dengan prosedur ilmiah namun masih memiliki keterbatasan yaitu: 1) Cakupan wilayah penelitian ini kurang luas karena hanya dilakukan di satu perusahaan dengan karakteristik responden yang kurang beragam. 2) Penelitian ini hanya sebatas meneliti empat variabel mengenai kepuasan kerja, stres kerja, lingkungan kerja dan turnover intention. Penelitian selanjutnya disarankan untuk dapat menambah variabel lain yang mampu mempengaruhi variabel turnover intention. 3) Tingkat kejujuran responden masih diragukan karena penelitian hanya menggunakan kuesioner dan wawancara dalam penelitian ini. 4) Penelitian ini hanya dilakukan dalam kurun waktu tertentu sedangkan lingkungan setiap saat berubah, sehingga penelitian ini perlu dilakukan kembali di masa mendatang. 


\section{SIMPULAN}

Kepuasan kerja memiliki pengaruh negatif terhadap turnover intention. Hal ini mengindikasikan bahwa semakin tinggi kepuasan kerja karyawan maka turnover intention akan semakin rendah, pihak perusahaan diharapkan selalu memperhatikan kepuasan kera karyawan untuk mempertahankan karyawan yang berkompeten.

Stres kerja memiliki pengaruh positif terhadap turnover intention. Hal ini berarti bahwa semakin tinggi tingkat stres kerja yang dialami karyawan maka tingkat turnover intention juga semakin meningkat, dari pihak perusahaan diharapkan membuat suatu sistem yang dapat menekan terjadinya stres kerja seperti melakukan rotasi pekerjaan sehingga karyawan tidak monoton dan bosan dengan pekerjaan nya. Lingkungan kerja pengaruh negatif terhadap turnover intention. Hal ini mengindikasikan bahwa ketika lingkungan kerja perusahaan kurang baik dan mengalami ketidakpuasan dalam bekerja maka turnover intention karyawan akan mengalami peningkatan. Pihak Human Resource Development (HRD) perusahaan hendaknya mengkaji ulang dalam pemberian tugas pada karyawan, agar karyawan tidak terbebani dengan pekerjaan yang begitu banyak sehingga menimbulkan stres dalam bekerja dengan cara memberikan pekerjan sesuai dengan keahlian dan melakukan pelatihan agar karyawan tidak berniat meninggalkan organisasi.

Pihak perusahaan hendaknya dapat lebih meningkatkan kepuasan kerja karyawan. Hal tersebut dapat diwujudkan dengan cara menambah kegiatan training sehingga dapat meningkatkan keterampilan karyawan dalam bekerja sehingga karyawan merasa puas dalam melakukan pekerjaannya. Diharapkan untuk peneliti selanjutnya dapat mengkaji lebih dalam tentang kepusan kerja, stres kerja, dan lingkungan kerja berpengaruh terhadap turnover intention karyawan agar diperoleh gambaran yang lebih lengkap lagi, sehingga diharapkan hasil penelitian yang akan datang lebih baik dari penelitian ini.

\section{REFERENSI}

Alamsyah, A., \& Kusumadewi, I. (2016). Pengaruh Stres Kerja, Kepuasan Kerja, Dan Kepuasan Atas Gaji Terhadap Turnover Intention Karyawan (Pt. Adira Semesta Idustry Cabang Ii Sumedang). Jurnal J-Ensitec, 3(1), J. J-Ensitec.

Anatan, L., \& Ellitan, L. (2007). Manajemen Sumber Daya Manusia Dalam Bisnis Modern. Bandung: Alfabeta.

Anggun, W. W. (2013). Pengaruh Lingkungan Kerja Terhadap Motivasi Kerja Pada Perusahaan Daerah Air Minum Tirta Khatulistiwa Kota Pontianak. Jurnal Manajemen Update, 2(2), 80-92.

Ardana, I. K., Mujiati, N. W., \& Utama, I. W. M. (2012). Manajemen Sumber Daya Manusia (1st ed.). Yogyakarta: Graha Ilmu.

Ariana, I. W. T., \& Riana, I. G. (2013). Pengaruh Kepemimpinan, Kompensasi dan Disiplin Kerja Terhadap Kinerja Karyawan Pada Hotel Cendana Resort \& Spa Ubud. E-Jurnal Manajemen Universitas Udayana, 2(1). 
Budiyono, R. (2016). Analisa Pengaruh Kepuasan Kerja, Stres Kerja, Dan Komitmen Organisasi Terhadap Turnover Intention (Studi Pada Pt. Duta Service Semarang). Jurnal Stie Semarang, 8(1), 37-53.

Chairani, H. (2014). Pengaruh Komitmen Organisasi, Kepuasan Kompensasi, Kepuasan Kerja dan LingkungannKerja Terhadap Turnover intentions Pada PT XYZ, tbk. Jurnal Manajemen, 2(2), 33-40.

Chandio, J. A., Jhatial, A. A., \& Mallah, R. (2013). Modeling The Relationship Of Unclear Career Development With Jib Dissatisfaction, Job Stres and Employees Turnover Intention: Structural Equation Modeling Approach. Journal of Arts Humamanities, 41(41), 55-57.

Chaudhry, A. Q. (2012). The Relationship Beetwen Occupational Stres and Job Satisfaction: The case of Pakistan Universities. International Education Studies, 5(3), 212-221.

Chen, C.-F. (2006). Job satisfaction, organizational commitment, and flight attendant turnover intentions: A note. Journal of Air Transport Management, 12, 274-276.

Dharma, C. (2013). Hubungan Antara Turnover Intention Dengan Komitmen Organisasional di PT. X Medan. Jurnal Ekonomi Dan Bisnis Jurusan Administrasi Niaga Politeknik Negeri Medan, 1(2), 1-9.

Febriani, T., \& Indrawati, D. (2013). Pengaruh motivasi, kompensasi, serta lingkungan kerja fisik terhadap kinerja karyawan hotel The Niche Bali. Jurnal Manajemen Universitas Udayana, 2(5), 541-551.

Giauque, D. (2014). Attitudes Toward Organizational Change Among Public Middle Managers. Public Personnel Managemen, 44(1), 70-98.

Grant, K., Cravens, D. W., Low, G. S., \& Moncrief, W. C. (2001). The role of satisfaction with territory design on the motivation, attitudes, and workoutcomes of salespeople. Journal of the Academy of Marketing Science, 29(2), 165-178.

Griffin, \& Moorhead. (2014). Organizational Behavior. Managing people and organizations (11th ed.).

Hanafiah, M. (2014). Pengaruh Kepuasan Kerja dan Ketidakamanan Kerja (JobInsecurity) dengan Intensi Pindah Kerja (Turnover) pada Karyawan PT. Buma Desa Suaran Kecamatan Sambaliung Kabupaten Berau. E-Journal Psikologi, 1(3), 303-312.

Harman, W. S., Blum, M., Stefani, J., \& Taho, A. (2009). Albanian Turnover: is The Job Embeddedness Construct Predictive in an Albanian Context? Institute of Behavioural and Applied Management, 195.

Holtom, B. C., \& O’Neill, B. S. (2004). Job Embeddedness: A Theoretical Foundation For Developing a Comprehensive Nurse Retention Plan. JONA, 
$34(5)$.

Humala, R. (2014). Kepemimpinan Transformasional Dengan Komitmen Organisasi Karyawan. JIPT, 2(2), 2301-8267.

Indrayanti, D. P., \& Riana, I. G. (2016). Pengaruh Kepuasan Kerja terhadap Turnover Intention melalui mediasi Komitmen Organisasional pada PT. CIOMAS ADISATWA di Denpasar. E-Jurnal Manajemen Unud, 5(5), 2727-2755.

Iqbal, S., Ehsan, S., \& Rizwan, M. (2014). The impact of organizational commitment, job satisfaction, job stres, and leadership support on turnover intention in educational institutes. International Jurnal of Human Resource Studies, 4(2), 181-195.

Irbayuni, S. (2012). Pengaruh Kompensasi, Kepuasan Kerja, dan Komitmen Organisasi Terhadap Keinginan Untuk Pidah Kerja Pada PT. Surya Sumber Daya Energi Surabaya. Jurnal NeO-Bis, 6(8).

Jehanzeb, K., Rasheed, A., \& Rasheed, M. F. (2013). Organizational Commitment and Turnover Intentions: Impact of Employee's Training in Private Sector of Saudi Arabia. International Journal Of Business\& Management, 8(8), 79-90.

Kabungaidze, T., Mahlatshana, N., \& Ngirande, H. (2013). The Impact of Job Satisfaction and Some Demographic Variables on Employee Turnover Intentions. International Journal of Business Administration, 4(1), 53-65.

Kardam, B. L., \& Rangnekar, S. (2012). Job satisfaction: investigating the role of experience and education. International Referred Research Journal, 3, 622.

Kaswan. (2015). Sikap Kerja Dari Teori dan Implementasi Sampai Bukti. Bandung: Alfabeta.

Ksama, I. B. P. T. (2016). Pengaruh Leader-Member Exchange, Role Stres dan Perceived Organizational Support terhadap Turnover Intention pada Karyawan Hotel Griya Santrian Sanur. Fakultas Ekonomi dan Bisnis.

Mamewe, L. (2015). Stres Kerja dan Iklim Organisasi Serta Pengaruhnya Terhadap Turnover Intention Dengan Kepuasan Kerja Sebagai Variabel Pemediasi. Jurnal Riset Bisnis Dan Manajemen, 3(4), 358-371.

Manurung, M. T., \& Ratnawati, I. (2012). Analisis Pengaruh Stres Kerja dan Kepuasan Kerja terhadap Turnover Intention Karyawan: Studi pada STIKES Widya Husada Semarang. Journal of Management, 1(2), 145-157.

Parvaiz, L., Saba, B., Ambar, K., \& Yasir, A. F. (2015). Impact of Stresors (Role conflict, Role overload, Leadership Support and Organizational Politics) on Job Stres and its Subsequent Impact on Turnover Intention. International Journal of Business and Management Invention, 4(10), 52-63. 
Puangyoykeaw, K., \& Yuko, N. (2015). Organizational commitment and turnover intention in low-skilled immigrant workers in Thailand: an impirical assessment of need satisfaction, job satisfaction and overall life satisfaction factors. International Journal of Business and Management, 10(5), 98-112.

Putra, B. R. (2012). Pengaruh job stresor terhadap turnover intention dengan kepuasan kerja sebagai variabel pemediasi. Jurnal Studi Manajemen Indonesia, 1(2), 72-81.

Putra, I. B. G. S., \& Rahyuda, A. G. (2016). Pengaruh Kompensasi, Lingkungan Kerja Dan Perceived Organizational Support (POS) Terhadap Retensi Karyawan. E-Jurnal Manajemen Unud, 5(2), 810-837.

Qureshi, M. I., Iftikar, M., Abbas, S. G., Hassan, U., \& Khan, K. (2013). Relationship Between Job Stres, Workload, Environment and Employees Turnover Intention: What We Know, What Should We Know. Jurnal World Applied Sciences, 23(6), 764-770.

Rahmawanti, N. P., Swasto, B., \& Prasetya, A. (2014). Pengaruh lingkungan kerja terhadap kinerja karyawan (Studi pada karyawan Kantor Pelayanan Pajak Pratama Malang Utara). Jurnal Administrasi Bisnis, 8(2), 1-9.

Rizwan, M. (2014). Preceding to employee satisfaction and turnover intention. Preceding to Employee Satisfaction and Turnover Intention, 4(3), 87-106.

Robbins, S., Judge, T. A., Millett, B., \& Boyle, M. (2013). Organisational Behaviour (8th ed.). AU: Pearson Higher Education.

Rumada, G., \& Utama, I. W. M. (2013). Pengaruh Kompensasi, Kepemimpinan, dan Lingkungan Kerja Fisik Terhadap Kepuasan Kerja Karyawan Hotel Taman Harum Ubud Gianyar. E-Jurnal Manajemen Unud, 2(1), 106-120.

Saeka, I. P. A. P. (2016). Pengaruh Kepuasan Kerja, Komitmen Organisasional dan Stres Kerja Terhadap Turnover Intention Karyawan Pt. Indonusa Algaemas Prima Bali. Fakultas Ekonomi dan Bisnis Universitas Udayana.

Sari, N. R., Hakam, M. S., \& Susilo, H. (2015). Pengaruh Kepuasan Kerja Terhadap Turnover Intention (Studi Pada AJB Bumiputera 1912 Kantor Wilayah Jatim II/Malang). Jurnal Administrasi Bisnis, 27(1), 1-8.

Sari, N. W. A. Y. M., Sudibya, I. G. A., \& Rahyuda, A. G. (2016). Pengaruh Work-Family Conflict dan Stres Kerja Terhadap Kepuasan Kerja dan Turnover Intention Karyawan Wanita. E- Jurnal Fakultas Ekonomi Dan Bisnis Universitas Udayana, 5(3), 629-658.

Sari, R. (2012). Pengaruh Kepemimpinan, Motivasi dan Stres Kerja Terhadap Kinerja Karyawan pada Bank Syariah Mandiri Kantor Cabang Makassar. Jurnal Analisis, 1(1), 87-93.

Sari, R. N. (2014). Pengaruh Kepuasan Kerja, Stres Kerja Dan Komitmen Organisasi Terhadap Turnover Intention (Pada Hotel Ibis Yogyakarta) 
(Universitas Negeri $\quad$ Yogyakarta). $\quad$ Retrieved from https://eprints.uny.ac.id/15137/1/SKRIPSI.pdf

Sewwandi, D. V. S., \& Perere, G. D. N. (2016). The Impact of Job Stres on turnover Intention: A Study of Reputed Apparel Firm in Sri Lanka. Journals \& Proceedings University of Sri Jayewardenepura, 3(1), 223-229.

Sianipar, A. R., \& Haryanti. (2014). Hubungan Komitmen Organisasi dan Kepuasan Kerja dengan Intensi Turnover pada Karyawan Bidang Produksi CV. X. Jurnal Psikodimensia, 13(1), 98-114.

Siddiqui, A. A., \& Raja, A. J. (2015). Antecedents of Employees' Turnover Intentions: Evidence from Private Educational Institutions. American Journal of Economics and Business Administration, 7(4), 160-165.

Suciati, Haryono, A. T., \& Minarsih, M. M. (2015). Pengaruh Job Insecurity dan Stres kerja Terhadap Turnover intention Pegawai pada karyawan PT. Berkat Abadi Surya Cemerlang Semarang (HO). Jurnal Administrasi Bisnis, 1(1), $1-12$.

Sutanto, E. M., \& Gunawan, C. (2013). Kepuasan Kerja, Komitmen Organisasional dan Turnover Intention. Jurnal Mitra Ekonomi Dan Manajemen Bisnis, 4(1), 76-88.

Syahronica, G., Hakam, M. S., \& Ruhana, I. (2015). Pengaruh kepuasan kerja dan stres kerja terhadap turnover intention (studi pada karyawan epartemen dunia fantasi PT. pembangunan jaya Ancol, tbk). Jurnal Administrasi Bisnis, 20(1), 1-6.

Taiwo. (2010). The Influence of Work Environment on Workers Productivity: A Case of Selected Oil and Gas Industry in Lagos, Nigeria. African Journal of Business Management, 4(3), 299-307.

Verina, R. E. (2014). Analisis Pengaru Stres Kerja, Beban Kerja dan Lingkungan Kerja Terhadap Turnover Intention Karyawan Pada PT. XL Axiata Tbk. Universitas Bina Nusantara.

Waspodo, A. A., Handayani, N. C., \& Paramita, W. (2013). Pengaruh Kepuasan Kerja dan Stres Kerja terhadap Turnover Intention pada Karyawan PT. Unitex di Bogor. Jurnal Riset Manajemen Sains Indonesia (JRMSI), 4(1), 97-115.

Widodo, D. S. (2014). Influence of Leadership dan Work Environment to Job Statisfaction dan Impact to Employee Performance Study on Industrial Manufacture in West Java. Journal of Economics Dan Sustainable Development.

Wursanto, I. (2009). Dasar-Dasar Ilmu Organisasi (2nd ed.). Yogyakarta: ANDI.

Yaqin, M. A. (2013). Pengaruh Kepuasan Kerja dan Komitmen Organisasi terhadap Turnover Intention Karyawan Kjpp Toha, Okky, Heru \& Rekan 
Desak Putu Rijasawitri, Pengaruh Kepuasan Kerja...

Cabang Surabaya. Jurnal Ilmu Manajemen, 1(2), 919-930.

Yunita, N. K. L., \& Putra, M. S. (2015). Pengaruh Keadilan Organisasi dan Lingkungan Kerja terhadap Turnover Intention. E-Jurnal Manajemen Unud, 4(5).

Zhao, E., \& Liu, L. (2010). Comments of Development of Job Embeddedness About Study to Turnover and Exploration into Application in Enterprises. Asian Social Science, 6(6), 63-64. 